\title{
Stability-Indicating RP-TLC/Densitometry Determination of Raloxifene Hydrochloride in Bulk Material and in Tablets
}

\author{
A. A. Shirkhedkar, J. K. Rajput, D. K. Rajput, and S. J. Surana \\ Department of Pharmaceutical Chemistry, R.C. Patel Institute of Pharmaceutical Education and Research, Karwand Naka, Shirpur, \\ Dhule District 425 405, India \\ Correspondence should be addressed to A. A. Shirkhedkar, atulshirkhedkar@rediffmail.com
}

Received 15 February 2012; Accepted 16 March 2012

Academic Editor: Sibel A. Ozkan

Copyright (๑) 2012 A. A. Shirkhedkar et al. This is an open access article distributed under the Creative Commons Attribution License, which permits unrestricted use, distribution, and reproduction in any medium, provided the original work is properly cited.

\begin{abstract}
A stability-indicating RP-TLC/Densitometry method for analysis of Raloxifene hydrochloride both in bulk material and in tablets was developed and validated. Densitometric analysis of Raloxifene hydrochloride was carried out at $311 \mathrm{~nm}$ on TLC aluminium plates precoated with silica gel $60 \mathrm{RP}-18 \mathrm{~F}_{254} \mathrm{~S}$ as the stationary phase and methanol: water: ammonia $(95: 05: 0.1 \mathrm{v} / \mathrm{v})$ as mobile phase. Raloxifene hydrochloride was well resolved at $R_{f} 0.55 \pm 0.02$. The linear regression analysis data for the calibration plots showed good linear relationship with $r^{2}=0.9969 \pm 0.0015$ with respect to peak area in the concentration range 100-600 ng per band. The mean value \pm SD of slope and intercept was found to be $15.05 \pm 0.44$ and $201.9 \pm 29.58$ with respect to peak area. The limits of detection and quantification were $9.27 \mathrm{ng}$ and $27.10 \mathrm{ng}$, respectively. Raloxifene hydrochloride was subjected to acid and alkali hydrolysis, oxidation, dry heat, and photodegradation. The drug underwent degradation under basic and oxidation conditions. This indicates that the drug is susceptible to alkali hydrolysis and oxidation. The proposed developed RPTLC/Densitometry method can be applied for identification and quantitative determination of Raloxifene hydrochloride in bulk material and tablets.
\end{abstract}

\section{Introduction}

Raloxifene hydrochloride (RLX), [6-Hydroxy-2-(4-hydroxyphenyl) benzo [b] thien-3-yl] [4-[2-(1-piperidinyl)-ethoxy] phenyl]-methanone-, hydrochloride (Figure 1) is a selective estrogen receptor modulator (SERM) used in the treatment of osteoporosis in postmenopausal women [1]. Clinically, it is effective in the treatment of breast cancer $[2,3]$.

Literature survey revealed that RLX was analyzed by HPLC [4-9], Stability-indicating UPLC [10], and several UV-spectrophotometric [11-14] in pharmaceutical formulations. Few methods such as LC-MS-MS [15] and HPLC [16] have been reported for estimation of RLX in biological samples. Although the RP-HPLC and UPLC procedures are accurate and effective means of assaying RLX, they are time and solvent consuming, and therefore, disadvantageous for serial estimation for a large number of samples [17]. However, the prominent application of HPTLC is that many samples can be run simultaneously using a small quantity of mobile phase unlike HPLC, thus reducing the analysis time and cost per analysis. In-reverse phase chromatography, polar mobile phase is used and the stationary phase is nonpolar. It is increasingly being experienced that different components of formulation which could not be resolved using normal-phase TLC could easily be resolved by reversephase TLC. Further, in RP-TLC, the impurities either at starting line or near the solvent front can be detected [18].

In view of the above factors, an HPTLC method was well thought-out, to be cheaper, faster, and sometimes more efficient than RP-HPLC and UPLC. From the literature survey, it is revealed that no stability-indicating RP-TLC/Densitometry method has been reported in the literature for analysis of RLX as bulk material or in pharmaceutical formulations.

Hence, the objective of the present investigation was to develop a simple stability-indicating RP-TLC/Densitometry method offering lower analysis time and less cost per analysis for estimation of RLX in bulk material and in tablets and to validate the method according to the ICH guidelines $[19,20]$. 


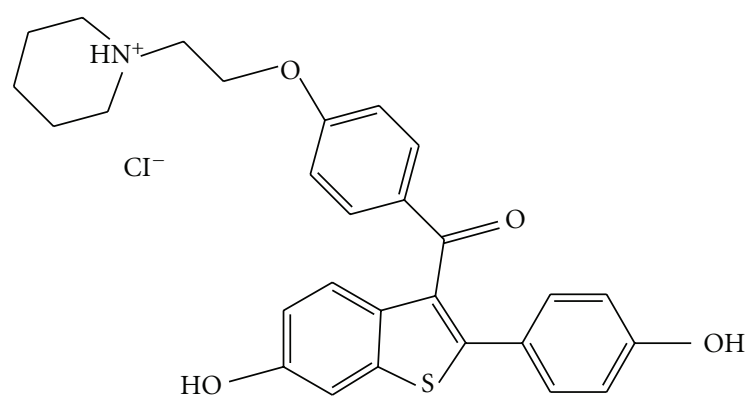

FIgURE 1: Chemical structure of Raloxifene hydrochloride (RLX).

\section{Experimental}

2.1. Chemicals and Reagents. Raloxifene hydrochloride (RLX) was procured from Cipla India Ltd, Mumbai, India. All chemicals and reagents used were of Analytical grade and were purchased from Merck Chemicals, India.

2.2. HPTLC Instrumentation. Chromatography was performed on aluminium plates precoated with Silica gel 60 RP-18 $\mathrm{F}_{254} \mathrm{~S}(20 \times 10 \mathrm{~cm}$, E. Merck, Germany). The plates were prewashed with methanol and activated at $100^{\circ} \mathrm{C}$ for $10 \mathrm{~min}$ prior to chromatography. The samples were spotted in the form of bands of $6 \mathrm{~mm}$ width with a Camag microlitre syringe using a Camag Linomat 5 applicator with a constant rate of application, $150 \mathrm{~nL}$ per second. Linear ascending development with methanol: water : ammonia $(95: 05: 0.1 \mathrm{v} / \mathrm{v})$ as mobile phase was performed in a 20 $\times 10 \mathrm{~cm}$ twin-trough glass chamber (Camag), with tightly fitting lid, previously saturated with mobile phase vapour for $25 \mathrm{~min}$ at room temperature $\left(25 \pm 2^{\circ} \mathrm{C}\right)$. The development distance was $8 \mathrm{~cm}$. After development, the plates were dried in current of air by an air dryer. Densitometric scanning was then performed at $311 \mathrm{~nm}$ with a Camag TLC Scanner 3 in absorbance mode operated by winCATS software. The source of radiation was a deuterium lamp. Slit dimensions were $5 \mathrm{~mm} \times 0.45 \mathrm{~mm}$ and the scanning speed $20 \mathrm{~mm}$ per second.

2.3. Preparation of Stock Standard Solution and Linearity Study. Stock standard solution was prepared by dissolving $10 \mathrm{mg}$ of RLX in $10 \mathrm{~mL}$ methanol. From it, appropriate volume $0.2-1.2 \mathrm{~mL}$ was transferred into six separate $10 \mathrm{~mL}$ volumetric flask and volume was made up to the mark with methanol. With the help of linomat 5 applicator, $5 \mu \mathrm{L}$ of each solution was applied on RP-TLC plates to obtain concentration in the range of 100 to $600 \mathrm{ng}$ per band, developed and scanned as described above.

2.4. Preparation of Sample Solution. Twenty tablets (RALISTA, label claim: $60 \mathrm{mg}$ of RLX per tablet) were weighed and crushed into fine powder. The quantity of powdered drug equivalent to $50 \mathrm{mg}$ of RLX was weighed and transferred in $100 \mathrm{~mL}$ volumetric flask containing $50 \mathrm{~mL}$ methanol, sonicated for $10 \mathrm{~min}$, volume was adjusted to mark and filtered using $0.45 \mu \mathrm{m}$ filter (Millifilter, Milford, MA). From the filtrate $1.0 \mathrm{~mL}$ was further diluted to $10 \mathrm{~mL}$ with methanol. Appropriate volume $8 \mu \mathrm{L}$ was spotted for assay of RLX. The RP-TLC plates were developed and scanned as described above.

\subsection{Method Validation}

2.5.1. Precision. Repeatability of sample application and measurement of peak area were performed using six replicates of the same spot ( $400 \mathrm{ng}$ per band of RLX). The intra, and interday variation for the estimation of RLX was carried out at three different concentration levels of 200,300, and 500 ng per band.

2.5.2. Limit of Detection (LOD) and Limit of Quantification (LOQ). In order to determine detection and quantification limit, RLX concentrations in the lower part of the linear range of the calibration curve were used. From the stock standard solution RLX 100, 120, 140, 160, 180, and $200 \mathrm{ng}$ per band was applied in triplicate on RP-TLC plate. The LOD and LOQ were calculated using equation LOD $=3.3 \times \mathrm{N} / \mathrm{B}$ and $L O Q=10 \times N / B$, where "N" is standard deviation of the peak areas of the drugs $(n=3)$, taken as a measure of noise, and " $\mathrm{B}$ " is the slope of the corresponding calibration curve.

2.5.3. Specificity. The specificity of the method was checked by analyzing drug standard and sample. The band for RLX in sample was confirmed by comparing the $R_{f}$ values and spectra of the band with that of standard. The peak purity of RLX was assessed by comparing the spectra at three different levels, that is, peak-start $(S)$, peak-apex $(M)$, and peak-end (E) positions of the band.

2.5.4. Ruggedness. Ruggedness of the method was performed by spotting $400 \mathrm{ng}$ of RLX by two different analysts keeping same experimental and environmental conditions.

2.5.5. Accuracy. The preanalysed samples ( $200 \mathrm{ng}$ per band) were spiked with extra 80,100 , and $120 \%$ of the standard RLX, and the mixture was then reanalysed by the proposed method. At each level of the amount, three determinations were performed. This was done to check the recovery of the drug at different levels in the formulations.

2.5.6. Robustness. By introducing small deliberate changes in the mobile-phase composition, the effects on the results were examined. Mobile phases having different composition of methanol: water:ammonia (96:4:0.1 v/v) and $(94: 6: 0.1 \mathrm{v} / \mathrm{v})$ were tried and chromatograms were run. The amount of mobile phase was varied in the range of $\pm 2 \mathrm{~mL}$. The plates were prewashed by methanol and activated at 100 $\pm 5^{\circ} \mathrm{C}$ for 5 and $15 \mathrm{~min}$ prior to chromatography. Time from spotting to chromatography and from chromatography to scanning was varied from $0,20,40 \mathrm{~min}$.

2.5.7. Stability of Sample Solution in Methanol and Mobile Phase. To assess the stability of RLX in methanol and mobile 
TABLE 1: Repeatability and Intraday, Interday precision.

\begin{tabular}{lccc}
\hline Parameters & Concentration ng per band & \% Amount found & \% RSD \\
\hline Repeatability $(n=6)$ & 400 & 100.94 & 99.98 \\
& 200 & 101.44 & 1.67 \\
Intraday $(n=3)$ & 300 & 99.70 & 0.94 \\
& 400 & 99.50 & 0.41 \\
\hline & 200 & 99.68 & 1.37 \\
Interday $(n=3)$ & 300 & 101.97 & 1.33 \\
\end{tabular}

$n$ : number of determinations.

TABLe 2: Recovery studies.

\begin{tabular}{lcccc}
\hline Drug & Initial amount (ng per band) & Amount of drug standard added (\%) & \% Drug recovered & \% RSD $(n=3)$ \\
\hline & 200 & 0 & 100.20 & 99.78 \\
RLX & 200 & 80 & 99.74 & 1.2 \\
& 200 & 100 & 100.57 & 1.4 \\
\end{tabular}

$n$ : number of determinations.

phase; the sample solutions were separately prepared in methanol and mobile phase and stored at room temperature for 24 (h). The sample solutions were assayed at an interval of 6 (h) for $24(\mathrm{~h})$.

2.5.8. Stability of Sample Solution on RP-TLC Plate. The sample solution was applied on RP-TLC plate, kept for 72 (h), and scanned at an interval of 12 (h) as described above.

\subsection{Forced Degradation of $R L X$}

2.6.1. Acid, Base and Oxidation Degradation. Accurately weighed quantity $10 \mathrm{mg}$ of RLX was separately dissolved in $10 \mathrm{~mL}$ methanolic solution of $0.5 \mathrm{M} \mathrm{HCl}$ and $0.5 \mathrm{M} \mathrm{NaOH}$ and $3 \%(\mathrm{v} / \mathrm{v})$ hydrogen peroxide, respectively; solutions were kept for period of $12(\mathrm{~h})$ at room temperature in dark to avoid likely degradative effect of light. An appropriate volume $1.0 \mathrm{~mL}$ of above solution was taken, neutralized, and diluted up to $10 \mathrm{~mL}$ with methanol. The resultant solution was applied on RP-TLC plates in triplicates $(5 \mu \mathrm{L}$ each, i.e, 500 ng per band). The chromatogram was developed and scanned as described above.

2.6.2. Dry Heat Degradation. Accurately weighed quantity $10 \mathrm{mg}$ of RLX stored at $80^{\circ} \mathrm{C}$ for 24 (h) in an oven. It was transferred to $10 \mathrm{~mL}$ volumetric flask containing methanol and volume was made up to the mark. The $1.0 \mathrm{~mL}$ of above solution was taken and diluted up to $10 \mathrm{~mL}$ with methanol. The resultant solution was applied on RP-TLC plate in triplicate ( $5 \mu \mathrm{L}$ each, i.e, $500 \mathrm{ng}$ per band). The chromatogram was developed and scanned as described above.

2.6.3. Photodegradation. Accurately weighed quantity $10 \mathrm{mg}$ of RLX was dissolved in $10 \mathrm{~mL}$ methanol and solutions was kept for period of 24 (h) in light. An appropriate volume $1.0 \mathrm{~mL}$ of above solution was taken and diluted up to $10 \mathrm{~mL}$

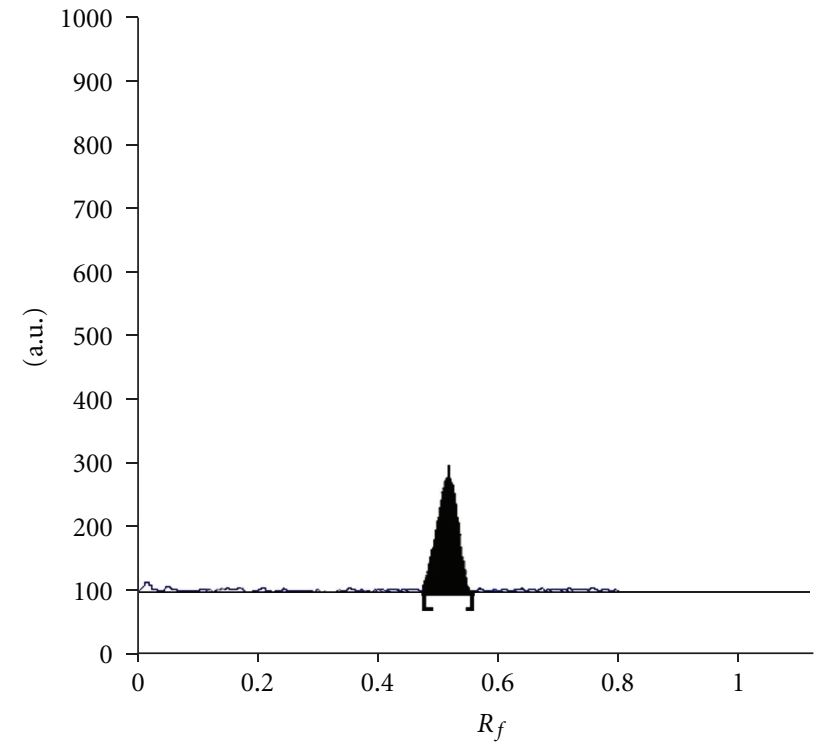

Figure 2: Chromatogram of RLX standard $\left(R_{f}: 0.55 \pm\right.$ $0.02)$ at $311 \mathrm{~nm}$, in mobile phase methanol:water:ammonia (95:05:0.1 v/v).

with methanol. The resultant solution was applied on RP-TLC plate in triplicate ( $5 \mu \mathrm{L}$ each, i.e, $500 \mathrm{ng}$ per band). The chromatogram was developed and scanned as described above.

\section{Results and Discussion}

3.1. Development of Optimum Mobile Phase. For the selection of appropriate mobile phase for RLX, several runs were exercised using mobile phases containing solvents of varying polarity, at different concentration levels. Among the different mobile-phase combinations employed, the mobile phase 
TABLE 3: Robustness of the method.

\begin{tabular}{lcc}
\hline Parameter & \pm SD of peak area & $\%$ RSD $(n=6)$ \\
\hline Mobile-phase composition: methanol : water : ammonia $(96: 04: 0.1 \mathrm{v} / \mathrm{v})$ & 50.89 & 1.5 \\
Mobile-phase composition: methanol : water : ammonia $(94: 06: 0.1 \mathrm{v} / \mathrm{v})$ & 52.74 & 1.6 \\
Mobile-phase volume $( \pm 2 \mathrm{~mL})$ & 44.91 & 1.4 \\
Development distance $( \pm 0.5 \mathrm{~cm})$ & 48.84 & 1.3 \\
Activation of TLC plate $( \pm 5 \mathrm{~min})$ & 44.97 & 0.9 \\
Duration of saturation $( \pm 5 \mathrm{~min})$ & 40.16 & 1.4 \\
Time from spotting to chromatography $( \pm 10 \mathrm{~min})$ & 49.34 & 0.9 \\
Time from chromatography to scanning $( \pm 10 \mathrm{~min})$ & & 1.2 \\
\hline
\end{tabular}

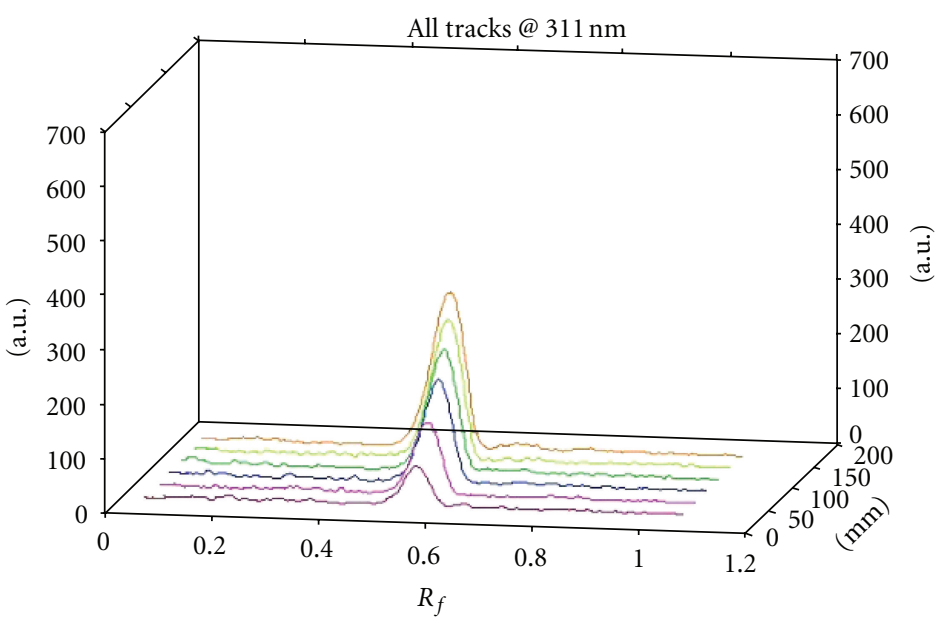

FIgURE 3: Three dimensional chromatograms of RLX sample (100-600 ng per band).

TABLE 4: Summery of validation parameter.

\begin{tabular}{lc}
\hline Parameter data & RLX \\
\hline Linearity range (ng per band) & $100-600$ \\
Correlation coefficient $\left(r^{2}\right)$ & 0.9969 \\
Limit of detection $(\mathrm{ng})$ & 9.27 \\
Limit of quantification $(\mathrm{ng})$ & 27.10 \\
Recovery $(n=3)$ & $99.74-100.57$ \\
\hline Ruggedness $(\%$ RSD) & \\
Analyst-I $(n=6)$ & 1.53 \\
Analyst-II $(n=6)$ & 1.33 \\
\hline Precision $(\% R S D)$ & \\
Repeatability of application $(n=6)$ & $0.96-1.49$ \\
Interday $(n=3)$ & $1.33-1.37$ \\
Intraday $(n=3)$ & $0.41-1.27$ \\
Robustness & Robust \\
Specificity & Specific \\
\hline
\end{tabular}

consisting of methanol:water:ammonia (95:05:0.1 v/v) gave a sharp and well-defined peak at $R_{f}$ value of $0.55 \pm$ 0.02 (Figure 2). Well distinct bands were found when the chamber was saturated with the mobile phase for $25 \mathrm{~min}$ at room temperature.

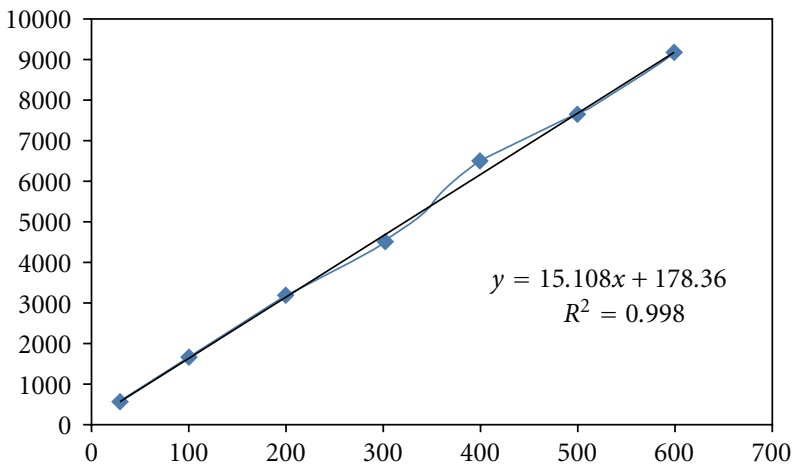

FIGURE 4: Calibration curve containing LOQ value as the lowest point.

3.2. Calibration Curve. The linear regression data for the calibration curves showed good linear relationship over the concentration range 100-600 ng per band. Linear regression equation was found to be $Y=15.05 X+201.9, r^{2}=$ 0.9969 (Figure 3).

\subsection{Validation of Method}

3.3.1. Precision. The precision of the developed method was represented in terms of \% relative standard deviation 
TABLE 5: Summary of forced degradation studies.

\begin{tabular}{lccc}
\hline Stress conditions & Time $(\mathrm{h})$ & Recovery $(\%)$ & $R_{f}$ of degradants \\
\hline $0.5 \mathrm{M} \mathrm{HCl}$ & 12 & 99.5 & No degradants formed \\
$0.5 \mathrm{M} \mathrm{NaOH}$ & 12 & 80.2 & $0.32,0.44,0.70$ \\
$3 \%(\mathrm{v} / \mathrm{v}) \mathrm{H}_{2} \mathrm{O}_{2}$ & 12 & 91.45 & 0.64 \\
Day light $(8(\mathrm{~h}) /$ day) & 24 & 99.9 & No degradants formed \\
Heat $\left(80^{\circ} \mathrm{C}\right)$ & 24 & 99.6 & No degradants formed \\
\hline
\end{tabular}

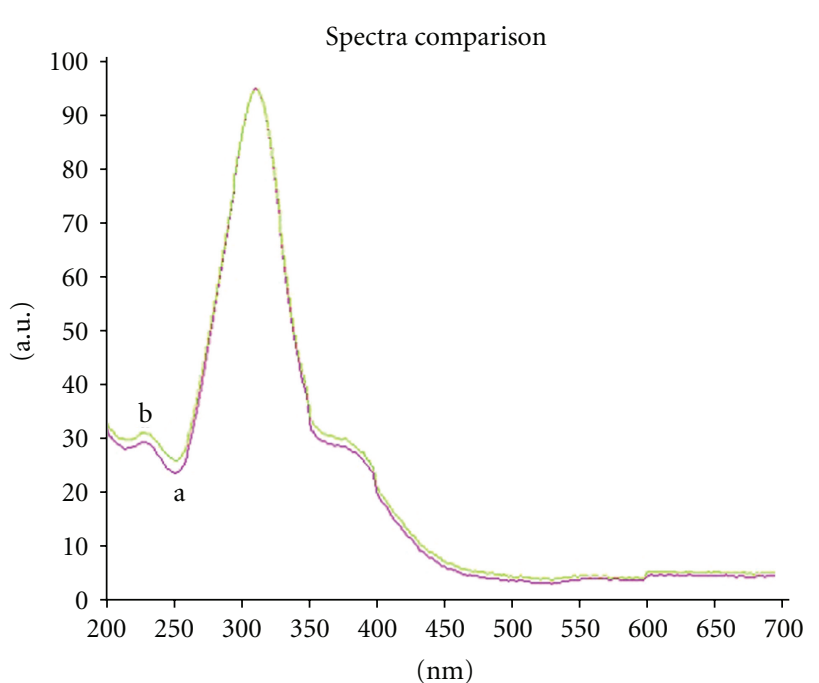

FIGURE 5: Peak purity spectra of RLX standard (a) and RLX extracted from tablets (b) scanned at peak-start, peak-apex and peak-end position.

(\% RSD) of the peak area. The results depicted indicated high precision of the method are presented in Table 1.

3.3.2. $L O D$ and $L O Q$. The LOD and LOQ were determined from the slope of the lowest part of the calibration plot. The LOD and LOQ were found to be $9.27 \mathrm{ng}$ and $27.10 \mathrm{ng}$, respectively, which indicates the sensitivity of the method is adequate (Figure 4 ).

3.3.3. Recovery Studies. The recovery studies were executed out at $80 \%, 100 \%$, and $120 \%$ of the test concentration as per ICH guidelines. The \% recovery of RLX at all the three levels was found to be satisfactory. The amounts of drug added and determined and the \% recovery are listed in Table 2.

3.3.4. Specificity. The peak purity of RLX was assessed by comparing the spectra at peak-start, peak-apex, and peakend positions of the band, that is, $r^{2}(S, M)=0.996$ and $r^{2}(M, E)=0.9988$. Good correlation $\left(r^{2}=0.9989\right)$ was also obtained between drug standard and drug extracted from tablet formulation (Figure 5).

3.3.5. Robustness of the Method. The standard deviation of peak areas was calculated for each parameter and \% R.S.D. was found to be less than $2 \%$. The low values of $\%$ RSD values indicate robustness of the method; results are shown in Table 3.

3.3.6. Solution Stability and Mobile Phase Stability. The stability study of RLX in methanol demonstrates no significant change in the chromatogram obtained.

Similarly, the stability study of RLX in mobile phase also does not show any noticeable change in the chromatogram.

3.3.7. Stability on Plate. No major changes were observed in chromagram when plate's were scanned at $0,12,24,36,48$, 72 (h) interval.

The validation of the method is summarized in Table 4 .

3.4. Analysis of the Marketed Formulation. A single spot at $R_{f}$ $0.55 \pm 0.02$ was observed in the chromatogram of the drug samples extracted from tablets. There was no interference from the excipients which routinely occur in the tablets. The mean $\%$ drug content was found to be $100.28 \%$ of the label claim.

3.5. Stability-Indicating Property. The results of the forced degradation study of RLX are summarized in Table 5. RLX showed degradation in alkali and oxidative conditions. In the base-induced degradation $(0.5 \mathrm{M} \mathrm{NaOH})$ study, RLX showed additional peaks at $R_{f}$ values $0.32,0.44,0.70$, and in oxidative degradation $\left(3 \%(\mathrm{v} / \mathrm{v}) \mathrm{H}_{2} \mathrm{O}_{2}\right)$ RLX showed only one additional peak at $R_{f} 0.64$ (Figure 6). The spots of the degraded products were well separated from the drug spots. The peak purity spectra of RLX recovered after degradation in $0.5 \mathrm{M} \mathrm{NaOH}, 3 \%(\mathrm{v} / \mathrm{v}) \mathrm{H}_{2} \mathrm{O}_{2}$ and $\mathrm{RLX}$ standard scanned at peak-start, peak-apex, and peak-end positions of the spot are shown in (Figure 7).

No additional peaks were found in acid, dry heat, and photodegradation. Therefore, RLX is stable in acidic, dry heat, and photoconditions.

\section{Conclusion}

The developed method was found to be simple, rapid, selective, sensitive, and suitable for determination of Raloxifene hydrochloride in bulk material and pharmaceutical dosage forms without any interference from excipients. As the method is stability-indicating one, it can be used to determine the purity of the drug available from various sources by detecting the related impurities. Furthermore, it can be concluded that the impurities present in the drug 


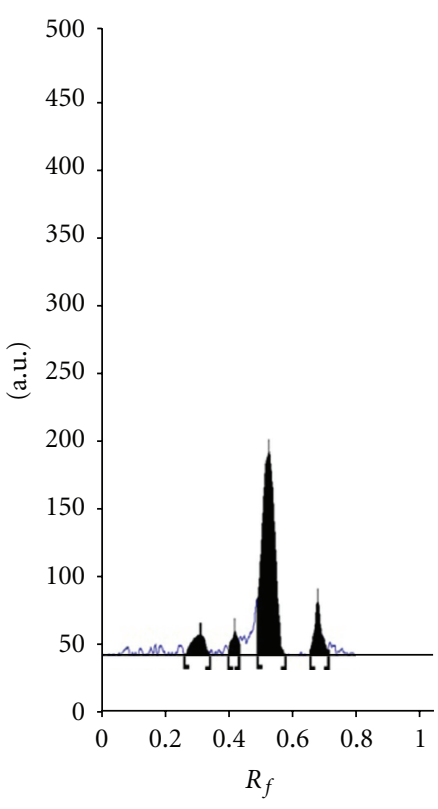

(a)

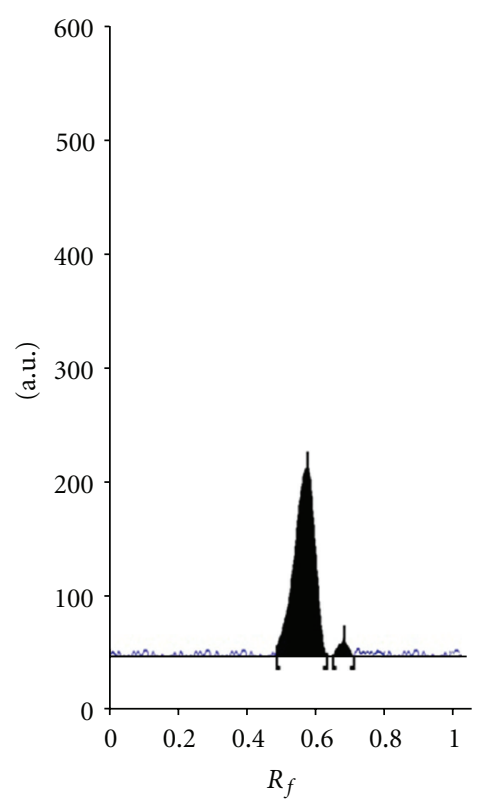

(b)

FIGURE 6: RP-TLC chromatogram obtained from forced degradation studies. (a) Base degradation (0.5 M NaOH, 12 (h), RT) showing three degradants at $R_{f}$ values $0.32,0.44$, and 0.70 for RLX. (b) Oxidative degradation ( $3 \%(\mathrm{v} / \mathrm{v}) \mathrm{H}_{2} \mathrm{O}_{2}, 12$ (h), RT) showing one degradant at $R_{f}$ values 0.64 for RLX.

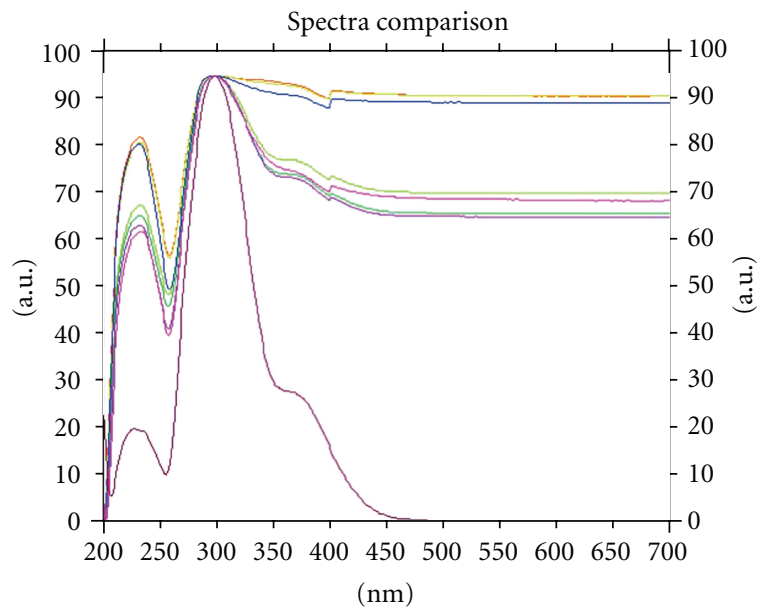

FIgURe 7: Peak purity spectra of RLX recovered after degradation in $0.5 \mathrm{M} \mathrm{NaOH}, 3 \%(\mathrm{v} / \mathrm{v}) \mathrm{H}_{2} \mathrm{O}_{2}$, degradants, and RLX standard scanned at peak-start, peak-apex, and peak-end positions.

could be due to hydrolysis or oxidation during processing and storage of the drug.

The proposed procedure fits precision and accuracy usually requested by official methods and can be used as a convenient alternative to HPLC analysis for quantitation of Raloxifene hydrochloride in both bulk and tablet dosage forms. Therefore, the proposed RP-TLC/Densitometry method can be used as an alternative tool in the drug quality control laboratories for quantitative determination of Raloxifene hydrochloride.

\section{Acknowledgment}

The authors are thankful to R.C. Patel Institute of Pharmaceutical Education and Research, Shirpur (MS), India, for providing the required facilities to carry out this research work.

\section{References}

[1] A. Smith, P. E. Heckelman, J. R. Obenchain, J. A. R. Gallipeau, M. A. D'Arecca, and S. Budavari, The Merck Index, Merck Research Laboratories, Whitehouse Station Readington, NJ, USA, 13th edition, 2001.

[2] S. R. Cummings, S. Eckert, K. A. Krueger et al., "The effect of raloxifene on risk of breast cancer in postmenopausal women," Journal of the American Medical Association, vol. 281, no. 23, pp. 2189-2197, 1999.

[3] T. Hol, M. B. Cox, H. U. Bryant, and M. W. Draper, "Selective estrogen receptor modulators and postmenopausal women's health," Journal of Women's Health, vol. 6, no. 5, pp. 523-531, 1997.

[4] D. Suneetha and A. Lakshmana Rao, "A new validated RPHPLC method for the estimation of raloxifene in pure and tablet dosage form," Rasayan Journal of Chemistry, vol. 3, no. 1, pp. 117-121, 2010.

[5] D. C. Pavithra and L. Sivasubramanian, "RP-HPLC estimation of raloxifene hydrochloride in tablets," Indian Journal of Pharmaceutical Sciences, vol. 68, no. 3, pp. 401-402, 2006.

[6] J. Trontelj, T. Vovk, M. Bogataj, and A. Mrhar, "HPLC analysis of raloxifene hydrochloride and its application to drug quality control studies," Pharmacological Research, vol. 52, no. 4, pp. 334-339, 2005. 
[7] B. Madhu, A. A. Kumara, S. Prashanth et al., "Sensitive and rapid HPLC method for the determination of raloxifene hydrochloride," Journal of Pharmacy Research, vol. 4, no. 3, pp. 582-584, 2011.

[8] K. Basavaiah, U. R. A. Kumar, and K. Tharpa, "Gradient HPLC analysis of raloxifene hydrochloride and its application to drug quality control," Acta Pharmaceutica, vol. 58, no. 3, pp. 347356, 2008.

[9] A. Sathyaraj, M. Rao, and V. Satyanarayana, "Gradient RPHPLC method for the detrmination of purity and assay of raloxifene hydrochloride in bulk drug," International Journal of Pharmaceutical Chemistry, vol. 1, no. 3, pp. 372-378, 2011.

[10] G. Srinivas, G. V. Kanumula, P. Madhavan et al., "Development and validation of stability indicating method for the quantitative determination of raloxifene hydrochloride and its related impurities using UPLC," Journal of Chemical and Pharmaceutical Research, vol. 3, no. 1, pp. 553-562, 2011.

[11] B. Kalyanaramu and K. Raghubabu, "Development of new analytical method for determination of raloxifene hydrochloride in formulations based on charge-transfer complex formation," International Journal of Analytical and Bioanalytical Chemistry, vol. 1, no. 2, pp. 29-33, 2011.

[12] D. C. Pavithra and L. Sivasubramanian, "New spectrophotometric determination of raloxifene hydrochloride in tablets," Indian Journal of Pharmaceutical Sciences, vol. 68, no. 3, pp. 375-376, 2006.

[13] K. Basavaiah and U. R. Anilkumar, "New sensitive spectrophotometric methods for the determination of raloxifene hydrochloride in pharmaceuticals using bromate-bromide, methyl orange and indigo carmine," E-Journal of Chemistry, vol. 3, no. 13, pp. 242-249, 2006.

[14] M. M. Annapurna, M. E. B. Rao, and B. V. Ravi Kumar, "Spectrophotometric determination of raloxifene hydrochloride in pharmaceutical formulations," E-Journal of Chemistry, vol. 4, no. 1, pp. 79-82, 2007.

[15] J. Trontelj, T. Vovic, M. Bogataj, and A. Mrhar, "Development and validation of liquid chromatography-tandem mass spectrometry assay for determination of raloxifene and its metabolites in human plasma," Journal of Chromatography B, vol. 855, no. 2, pp. 220-227, 2007.

[16] Z. Y. Yang, Z. F. Zhang, X. B. He, G. Y. Zhao, and Y. Q. Zhang, "Validation of a novel HPLC method for the determination of Raloxifene and its pharmacokinetics in rat plasma," Chromatographia, vol. 65, no. 3-4, pp. 197-201, 2007.

[17] S. A. Coran, M. Bambagiotti-Alberti, V. Giannellini, A. Baldi, G. Picchioni, and F. Paoli, "Development of a densitometric method for the determination of cephalexin as an alternative to the standard HPLC procedure," Journal of Pharmaceutical and Biomedical Analysis, vol. 18, no. 1-2, pp. 271-274, 1998.

[18] P. D. Sethi, High Performance Thin Layer Chromatography (Quantitative Analysis of Pharmaceutical Formulations), CBS Publishers, New Delhi, India, 1996.

[19] International conference on Harmonization ICH/CPMP guidelines Q2(R1), Validation of Analytical Procedures: Text and Methodology, ICH, Geneva, Switzerland, 2005.

[20] International Conference on Harmonization Q1A, Stability Testing of New Drug Substances and Products, ICH, Geneva, Switzerland, 1993. 


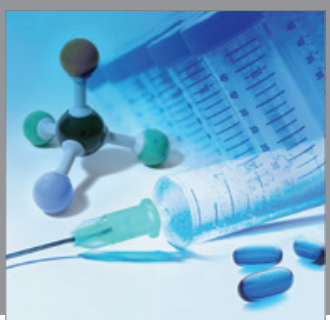

International Journal of

Medicinal Chemistry

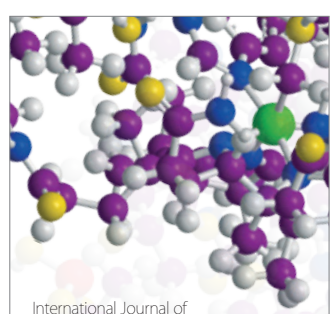

Carbohydrate Chemistry

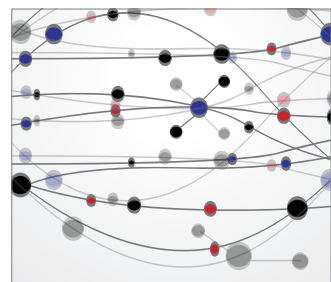

The Scientific World Journal
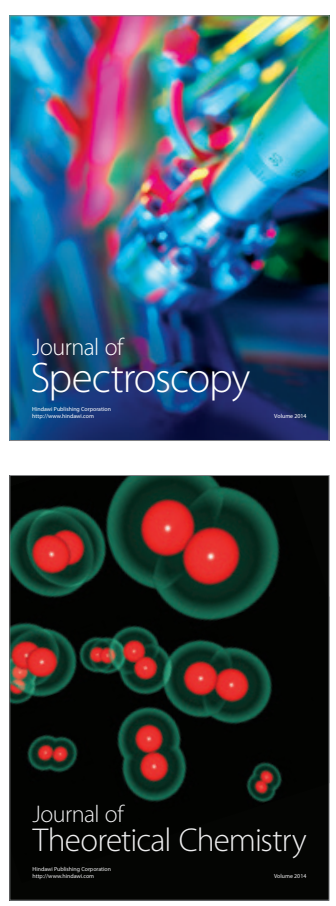
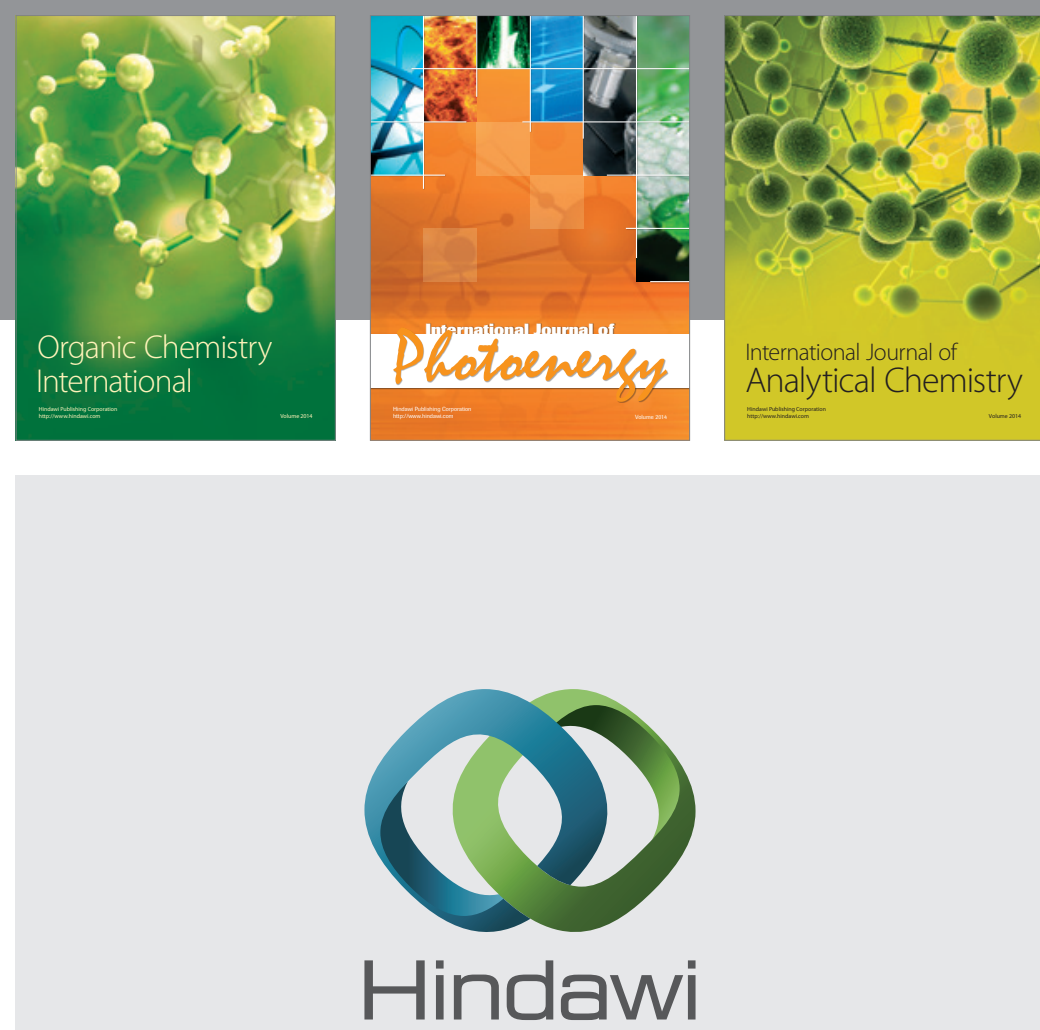

Submit your manuscripts at

http://www.hindawi.com
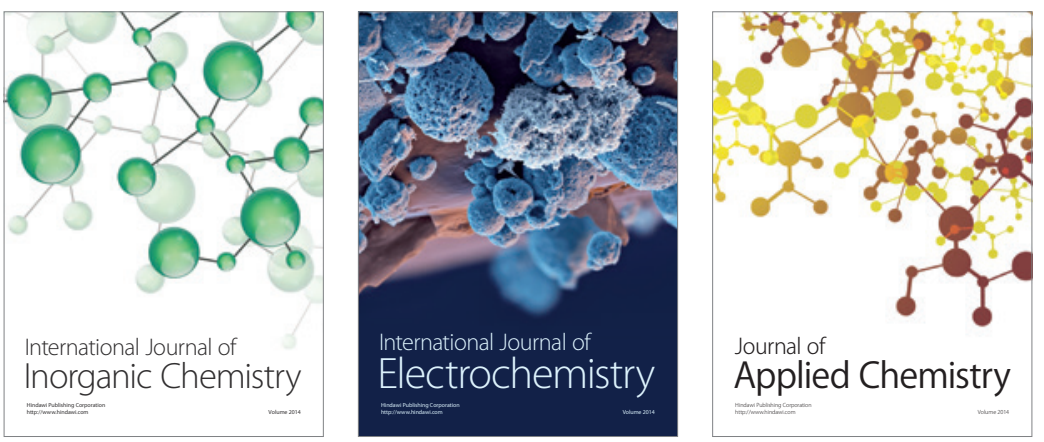

Journal of

Applied Chemistry
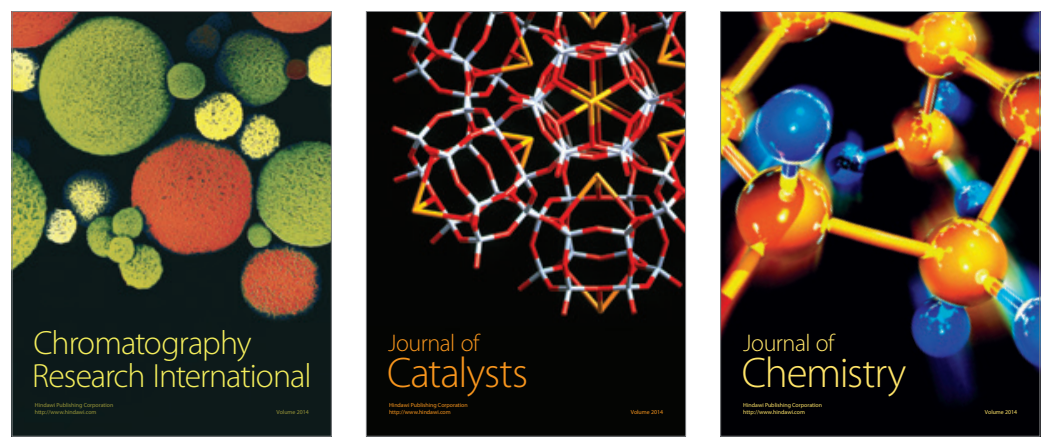
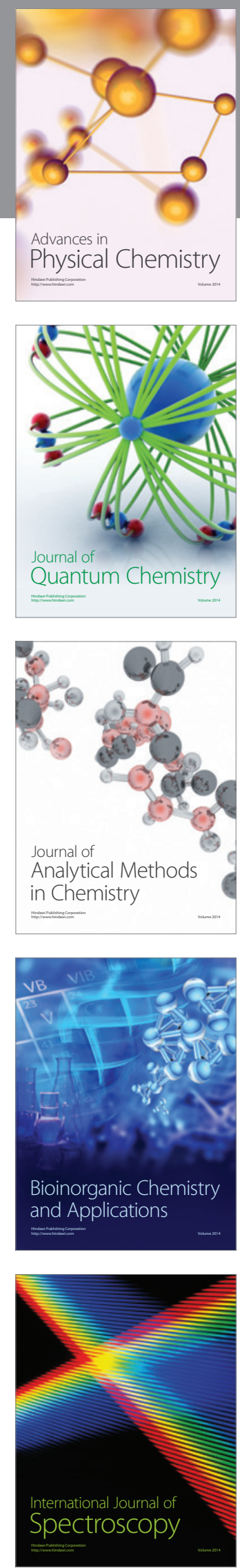